\title{
Objectivity versus narrative coherence: science, environmental policy, and the U.S. Data Quality Act
}

\author{
Charles N. Herrick* \\ Stratus Consulting, 1990 L Street, N.W. Suite 420, Washington, DC 20036, USA
}

\begin{abstract}
In this paper it is argued that mischaracterization concerning the use of science in the U.S. policy process has lead to unreasonable expectations about the role that scientific information can play in the development of environmental and public health policies. This in turn has lead to implementation of misguided and self-defeating policy initiatives designed to ensure the objectivity or "soundness" of scientific inputs to the policy process. This argument is illustrated through critical deconstruction of the recently implemented U.S. Data Quality Act. The interpretative and socially constructed character of scientific findings is well established across fields as diverse as the philosophy and history of science, science and technology studies, and the sociology of science. It is demonstrated that scientific assessment in a policy context rarely - if ever - lends itself to dichotomous characterizations such as "objective/non-objective." This suggests the futility of policy initiatives designed to insure the purported objectivity of data and information used for political deliberation and/or policy decisions. An alternative perspective regarding the role of science in political deliberation and public policy is offered, drawing on the narrative school of policy analysis as articulated by Giandomenico Majone, Emery Rowe, Barry Bozeman and others. Under this view, scientific findings draw much of their validity through the context of their application in policy narratives. As a coda to the essay, it is suggested that similar perspectives underlie debates concerning both The Skeptical Environmentalist and the Data Quality Act.
\end{abstract}

(C) 2004 Elsevier Ltd. All rights reserved.

Keywords: Science policy; Environmental policy; Data Quality Act

\section{Science and the "grounding" for environmental and public health policy}

There is widespread concern regarding how science is being used to support decision-making. Many believe that the canons of scientific method are frequently, perhaps even routinely, subverted through interaction with political processes. In the U.S., the mantle of "sound science" is increasingly paraded as a lacking, but necessary, precondition for the formulation and execution of environmental, public health, consumer safety and other policy initiatives. For example, a briefing document presented to the newly inaugurated Bush Administration asserted that the U.S. Environmental Protection Agency (EPA) and other government bureaus fail follow rigorous scientific protocols, and "[t]oo often, the result is decision-making based on incomplete data or policy-driven scientific assessments, as opposed to an objective, science-based analysis of the economic, public health, and environmental impacts of policy options" (Business Roundtable, 2001). This theme has echoed in recent Congressional deliberations concerning the possible el-

\footnotetext{
* Corresponding author. Tel.: +1-202-466-3731; fax: +1-202-466-3732.

E-mail address: cherrick@stratusconsulting.com (C.N. Herrick).
}

evation of the EPA to Cabinet status, with legislative proposals keyed to concurrent implementation of "protocols" to assure that regulations and policy initiatives are based upon peer reviewed, replicable, credible scientific findings and information (BNA Inc., 2003).

As Sheila Jasanoff has observed, the U.S. debate over the appropriate application of scientific input to the policy process tends to draw upon "uncritical and theoretically uninformed" characterizations of the scientific process (Jasanoff, 1990). For example, it is not uncommon to hear that time-honored standards of scientific proof should be applied to the application of scientific information in a policy setting. As one commenter puts it, "a basic tenet for science is for scientists to posit and test hypotheses and theories. Scientific progress is made by accepting or rejecting hypotheses at specified levels of confidence" (Winstanley, 2000). While consistent with popular belief and the folklore of science, such a formulation is too simplistic to illuminate the conduct of scientific assessments in any but the most trivial policy context. As Clark and Majone explain, it is important not to equate the adequacy of scientific assessments with their purported compliance with "rules for good practice. The vulgar version of the 'scientific method' taught in American schools presents just such rules: 'Do it 
this way, test the results, and the resulting knowledge will be scientific.' Nothing could be further from reality. Scientific inquiry involves creativity plus essential elements of craft skill. There is no 'standard operating procedure' that will guarantee good science, any more than there is one that will guarantee good painting" (Clark and Majone, 1985).

Part of the problem may reside with confusion ${ }^{1}$ regarding the legitimate differences between traditional, discipline-based scientific research, and science-policy assessment. Drawing on Russell and others, in this essay science will be understood as a "process of discovering new knowledge through research. Research is an orderly process of inquiry into the nature of things and the way they function. Basic research is inquiry aimed at understanding the physical, biological, social, and mathematical world around us." Science-policy assessment (or science assessment), on the other hand, is a process by which scientific and technological evidence is marshaled for the purpose of predicting, projecting, or otherwise characterizing the consequences of alternative courses of action. Science assessment includes analysis of the "quality of scientific understanding and identifying and bounding uncertainty so that decision makers can act with an appropriate interpretation of expected outcomes, results, benefits, costs, and risks (Russell et al., 1991). Science assessment also relates to development of interpretive information products intended to make stakeholders and the public aware of environmental issues and their potential impacts.

The distinction between science and science assessment is not well or widely understood, resulting in either inadvertent or willful conflation of the two processes. In this paper it is argued that mischaracterization of the role that science plays in the policy process has lead to unreasonable expectations about the role that scientific information can play in the development of environmental policies, and the consequent implementation of misguided policy mechanisms. This argument is illustrated through deconstruction of the recently implemented U.S. Data Quality Act.

The next section of the essay describes the Data Quality Act and its key provisions. The Data Quality Act is then explicated in terms of the principle of public right-to-know, especially as it pertains the arenas of public health and environmental policy. Next, literature in areas such as sociology of science, philosophical epistemology, and science and technology studies is summarized to illustrate the interpretive and socially constructed character of scientific findings and the significance of such constructions in a policy or political context. Drawing on several recent

\footnotetext{
${ }^{1}$ Some commentors argue that confusion is not so much the issue as willful and inappropriate conflation of the standards and expectations that underlie basic science and science assessment. Some argue that demands for increased scientific objectivity are merely a deliberate distraction or form of partisan temporizing (Planin, 2002).
}

cases, it is demonstrated that scientific findings tend to be "policy-agnostic" in the sense that they lend themselves to multiple interpretations and consistency with a wide range of policy alternatives, even those supported by political opponents; and similarly, that scientific assessment in a policy context rarely - if ever - lends itself to dichotomous characterizations, such as "objective/non-objective." With this framework established, several examples drawn from early implementation of the Data Quality Act are critiqued to illustrate the tenuousness of arguments tied to a simplistic, deterministic conception of objectivity. The main body of the essay concludes by articulating an alternative perspective regarding the application of science in a policy or decision context, drawing particularly from the narrative school of policy analysis as articulated by Giandomenico Majone, Emory Roe, and Barry Bozeman. This account, while primarily descriptive in nature, supports critique of current policy practices and provides theoretical underpinning for a more realistic conception of the role that science can play in politicized environmental and public health issues such as global warming, control of non-point pollution, and forest management.

A coda section at the end of the essay ties the rationale behind the Data Quality Act to debates concerning Bjorn Lomborg and The Skeptical Environmentalist (Lomborg, 2001). In particular, it is suggested that the same general mischaracterization of the scientific assessment process that underlies the Data Quality Act also animates the poles of the Lomborg debate.

\section{Ensuring the objectivity of information disseminated by federal agencies}

Known popularly as the Data Quality Act, Section 515(a) of the U.S. Treasury and General Government Appropriations Act for Fiscal Year 2001 (Public Law 106-554) is a two-paragraph "rider" directing the Office of Management and Budget (OMB) to develop and issue government-wide guidelines that "provide policy and procedural guidance to Federal agencies for ensuring and maximizing the quality, objectivity, utility, and integrity of information disseminated by Federal agencies" (U.S. Office of Management and Budget, 2002).

The Data Quality Act had its origins in a political dispute over air pollution (Regulation, 2002). When EPA proposed to tighten the National Ambient Air Quality Standards (NAAQS) for so-called "fine particulate" pollutants, opponents felt hamstrung by an inability to access and review some of the supporting scientific data because the research involved human subjects and was treated as confidential. One result was a successful effort to amend the Freedom of Information Act to apply to scientific data, also passed as a rider to a spending bill (Pielke, 2002a). The Data Quality Act was another outcome of the dispute over data access engendered by the debate over fine particulate NAAQS. 
Sponsored by Rep. Joanne Emerson (Democrat, Missouri), ${ }^{2}$ the Act was subject to no hearings and there is no legislative history indicating what Congress meant when it required agencies to establish processes to ensure and maximize the quality, objectivity, utility, and integrity of the information they disseminate (Noe et al., 2003). Instead, Congress instructed OMB (and ultimately the Office of Information and Regulatory Affairs within OMB) to provide guidance on how agencies should implement the Data Quality Act.

Released in January 2002, the OMB guidelines (U.S. Office of Management and Budget, 2002) for Section 515 direct agencies subject to the Paperwork Reduction Act (U.S. Code Collection, 44 U.S.C. 3502(1)) to:

- Issue their own information quality guidelines ensuring and maximizing the quality, objectivity, utility, and integrity of information, including statistical information, by no later than one year after the date of issuance of the OMB guidelines; ${ }^{3}$

- Establish administrative mechanisms allowing affected persons to seek and obtain correction of information maintained and disseminated by the agency that does not comply with OMB and agency-specific guidelines;

- Report to the Director of OMB the number and nature of complaints received by the agency regarding agency compliance with OMB guidelines concerning the quality, objectivity, utility, and integrity of information and how such complaints were resolved.

The definitions of "information" and "dissemination" establish the scope of the applicability of OMB's guidelines. "Information" means any communication or representation of knowledge such as facts or data, in any medium or form, including textual, numerical, graphic, cartographic, narrative, or audiovisual. "Dissemination" is defined to mean agency initiated or sponsored distribution of information to the public. An "Information Dissemination Product" is any book, paper, map, machine-readable material, audiovisual production, or other documentary material, regardless of physical form or characteristic, an agency disseminates to the public. This definition includes any electronic document, CD-ROM, or web page. ${ }^{4}$

As required by OMB, most federal agencies had developed and published their own information quality guidelines by October 2002. According to supporters and detractors

\footnotetext{
${ }^{2}$ It is widely reported that the Data Quality Act was promoted by an industry-sponsored lobby and consulting organization known as the Center for Regulatory Effectiveness (CRE). The CRE has an extensive and well-maintained Web site that contains much material and documentation relevant to the Data Quality Act and other information related policy matters (TheCre.com, 2003a).

3 Most federal agencies published guidelines by February 22, 2002.

4 Section 515 does not apply to "opinions, where the Agency's presentation makes it clear that what is being offered is someone's opinion rather than fact or the Agency's views. The definition of "dissemination" does not include distribution limited to correspondence with individuals or persons, press releases, archival records, public findings, subpoenas or adjudicative processes.
}

alike, the Data Quality Act has the potential to revolutionize the role of science in policy making. Quoted in the New York Times, a representative of the United States Chamber of Commerce characterized the Data Quality Act as "the biggest sleeper there is in the regulatory area and will have an impact ... far beyond anything people can imagine" (Revkin, 2002). As described in the Wall Street Journal, the Act "will require government agencies to ensure the quality of data they use when issuing new rules, regulations, and studies. For the first time, anyone will be able to challenge the data used in formulating government regulation, instead of just challenging the rules themselves" (Horvath, 2002).

\section{So what's wrong with objective information?}

The public's right-to-know about environmental and health-related risks is strongly founded in American political thought. As bluntly articulated by James Madison,

A popular Government without popular information or the means of acquiring it, is but a prologue to a farce or a tragedy or perhaps both. Knowledge will forever govern ignorance, and a people who mean to be their own governors, must arm themselves with the power knowledge gives. (Madison, 1910)

Over the past quarter century, the notion of informed consent or public right-to-know has been codified through numerous articles of law and regulation, especially in arenas such as public health, worker safety, and the environment. Indeed, most major U.S. environmental laws include provisions to enhance the public's right-to-know about environmental conditions and threats. Examples include the Emergency Planning and Community Right-to-Know Act (EPCRA), Safe Drinking Water Act, Clean Air Act Amendments, National Environmental Policy Act, and the Beaches Act. However, the technical complexity of modern systems renders this right nearly vacuous without active facilitation on the part of government (Wachbroit, 2001). In the United States, the Environmental Protection Agency and many state agencies are taking aggressive steps to enable and facilitate the public's awareness and understanding of environmental risks, partially through the creation of interpretive information products and Web-based data applications. Government agencies in the U.S. also invest significant time and effort to enhance the communicability of information released to the public, both through formal application of the principles of risk communication and through less formalized activities to assure meaningful stakeholder and public input and dialog (Davies, 1996; Fischhoff et al., 1993; National Research Council, 1989). There are also significant efforts in the non-governmental public sector to compile, interpret, and disseminate environmental and public health-related information. Exhibit 1 summarizes several Web-based information applications designed to help the public better understand 
Exhibit 1. Illustrative Environmental Information Products.

- Integrated Risk Information System (IRIS): IRIS is an electronic database containing information about human health effects that may result from exposure to various chemicals in the environment. Developed by EPA, IRIS contains descriptive and quantitative information on both carcinogenic and chronic, noncarcinogenic health effects.

- Window to my Environment: An EPA Web application that enables individuals to enter their address or ZIP code and obtain spatially configured information on permits, violations, air pollution concentrations, toxic chemical releases, hazardous waste sites, and other environmental and health-related data maintained by states and EPA.

- TRI Explorer: A Web site that consolidates data from EPA's Toxic Release Inventory, enabling the public to view environmental release information by facility, chemical, year, industrial type, and geographic region.

- RTK Net: Run by the non-profit, OMB Watch, RTK Net provides Web-based access to EPA and other federal data on chemical releases and accidents by facility, chemical compound, or geographic region.

- Earth 911-Beach Water Quality: Sponsored by Oceana Corportation and the Surfrider Foundation, this Web site consolidates state- and county-level information on beach closures, beach water quality, and coastal pollution.

environmental conditions and trends and to respond to potential health risks.

In recent years, critics have argued that Federal facilitation of the public's right-to-know constitutes "off-register" regulation, or an inappropriate form of policy entrepreneurship not supported by an agency's organic charter. It is contended that the government's practice of collecting and disseminating information about various business activities can place private entities in an "unfavorable light and resulting public and political pressures will force changes in private sector behavior." As OMB Associate Director, John Graham, has written, " a single statistic on a government [W]eb site can cause a consumer to change his or her diet, a producer to stop using a specific input, an employee to refrain from making an equal-opportunity claim, and a mayor's office to allocate scarce funds to one health program rather another" (Clean Air Report, 2002).

While the degree to which dissemination of environmental and public health-related data has forced behavioral changes or resulted in documented harm to individuals or commercial entities is arguable (Wagner, 2004; Echeverria and Kaplan, 2002; Herrick and Jamieson, 2001), it is hard in principle to criticize any effort to encourage government agencies to seek and use the best available data, to scrupulously check their facts, and to respond quickly and thoroughly to public complaints. However, there is another level upon which the Data Quality Act can be viewed as potentially counterproductive. The Data Quality Act has the potential to establish a sort of epistemic line in the sand for the public dissemination of information. If a document or other information product is deemed objective, an agency can disseminate it to the public; if it is not objective, it is subject to administrative and/or judicial review and possible "recall" from public distribution. This dynamic could have a chilling effect on public deliberation, especially as regards consideration of preliminary findings and data (Kaiser, 2003), thereby weakening the role of public discourse in policy formulation and regulatory oversight.

\section{Knowledge as a social construct, inquiry as a political process}

Most people understand that the political process synthesizes different viewpoints, perspectives, and interests. Political deliberation is a highly socialized process through which interests and values are articulated, communicated, and weighed for public consideration. Contemporary political theorists ranging from Lippman, to Dewey, to Habermas have placed great emphasis on the need for rich and thorough deliberation in a truly open and public context. It is through open deliberation that the public interest is presumed to emerge. The ultimate objective of the political process is to resolve alternative perspectives into a shared commitment to action. In other words, the goal of a political process is to reduce the scope of choice to a single alternative.

It is perhaps less well understood that the process of rational inquiry is also deliberative and socialized. In most circles of thought we have moved beyond the naive empiricist position that objectivity is a feature of brute phenomena, or that "facticity" somehow resides in the nature of things. We now understand that objectivity is an emergent construct, derived through deliberative interaction among peers. In Thomas Kuhn's seminal discussion of scientific paradigms, the concept of "discipline" is articulated as the vehicle through which scientific findings acquire meaning and authority. Disciplines, as Kuhn writes, provide "rules that limit both the acceptable solutions and the steps by which they are to be obtained" (Kuhn, 1970). Casting a wider net than Kuhn, Jay Schulkin outlines an especially rich depiction of the degree to which objectivity is a socially embedded notion:

The most general feature of what one does when making an objective claim is giving a plausible story. One states one's beliefs (or those most likely to be challenged) and the reasons for the beliefs, making the case for their viability by persuading an audience of the merits of the claim and subjecting the beliefs to criticism. What is persuasive 
or warranted varies according to the subject matter. In one case prediction may be the persuasive factor. In another, it may be the perspicacious analysis of a text. In both cases, what makes it objective is that it can be criticized, tested, or challenged in some form. The inquirer makes a case to which the community of inquirers can respond. (Schulkin, 1992)

The socialized nature of rational inquiry means that empirical characterizations can vary according to the context of their application or assessment. As Helen Longino points out, "[a] given item, event, or state of affairs can be correctly described in different ways depending on the points of view and interests of those describing it. For instance, 'the gray hat' and 'the hat on the banister' are descriptions that can be used to refer to the same hat. The consequences of emphasizing one aspect of the hat rather than another include the possibility of its receiving under one description an evidential assessment different from that received in a context in which some other aspect is emphasized" (Longino, 1990). Consider another example. A person's hand can be described in many different ways without exhausting possible or reasonable descriptions. A partial list of qualities might include size, color, and genetic structure. Qualities that would be essential for a genomics researcher would clearly be irrelevant to a mitten manufacturer (Herrick and Jamieson, 1995). Likewise, the quality of data required to support one characterization may be vastly different than that required for an alternative application. Consider something like the Missouri River Basin. A tourist brochure and map of the Missouri River Basin describing and depicting highlights of the 1804 Lewis and Clark expedition published by the U.S. National Park Service can and should be subject to very different quality parameters than, say, a navigational map of a specific reach of the Missouri River produced by the U.S. Army Corps of Engineers.

True descriptions of empirical objects are nearly inexhaustible, making it difficult to maintain the argument that a particular characterization is better, or more objective, than another for all purposes. Fredrick Waismann argued that the "open texture" of scientific findings makes it impossible to provide complete descriptions of most empirical concepts. For this reason, empirical claims can rarely be completely validated. More tests can always be demanded and additional descriptions can always be given. As Herrick and Jamieson argue, the open texture of empirical concepts means that science-based assessments of policy related issues can almost always be charged with "sins of omission (1995)." The open texture of scientific findings, then, will almost certainly export to policy assessments and information products that discuss, interpret, or otherwise apply those findings.

The following short case examples are selected to illustrate the open texture, or interpretive nature, of scientific findings in a policy context.

\subsection{Acidic deposition effects of surface waters}

In the early 1970s, U.S. scientists caught the public's attention by asserting that lakes in the Adirondack Mountains and other regions were dying from acid rain. Congress reacted to the ensuing public outcry and demanded large reductions in emissions of sulfur dioxide and nitrogen oxides from electric power plants in the Midwest. However, rust belt manufacturers and the coal and utility industries claimed that proposed emissions reductions would be very expensive, leading to severe unemployment in an already depressed region of the country. Pointing to scientific and technological uncertainties associated with the acid rain debate, President Carter signed the Acid Rain Act of 1980 (Title VII of the Energy Security Act of 1980 [P.L. 96-294]), creating a 10-year research program - the National Acid Precipitation Assessment Program (NAPAP).

One of NAPAP's primary objectives was to characterize and inventory the extent to which U.S. surface waters had been impacted by acidic deposition. Data from NAPAP's various surveys of surface water quality would then be used to assess emissions and deposition reductions necessary to reverse the impacts on surface water acidification. This process proved difficult because aquatic damage from acidic deposition can be characterized in several ways. If damages are characterized in terms of the number of water bodies affected, then predictions of decreased deposition appear to provide a substantial decrease in damages. If the same prediction is expressed in terms of the percentage of affected water bodies, then the decrease in damages appears less significant. It also matters whether acidity is characterized in terms of $\mathrm{pH}$ or acid neutralizing capacity; with gains expressed in terms of $\mathrm{pH}$ being smaller. Moreover, the choice of a baseline $\mathrm{pH}$ value (i.e., the "natural" acidity of a given body of water) can radically alter the number of acidic lakes and streams.

Numerous decisions must be made in order to frame an assessment of the impact that acidic deposition has on surface waters. A national scale depiction of the issue will tend to discount localized hot spots; a focus on chronic acidity will produce a different perspective than one that includes, or possibly emphasizes, short-term episodes; and analyses dealing with the current situation may inadvertently miss longer term processes threatening future degradation. Still another issue is whether chemical acidification has actually resulted in documented injury to aquatic life, and whether this injury is direct or indirect. All of these measures are valid, but no single one (or combination) of them is intrinsically more correct than the others. ${ }^{5}$

\footnotetext{
${ }^{5}$ Much of the acid rain discussion is taken from Herrick and Jamieson (1995).
} 


\subsection{Dioxin and human health risks}

The term dioxin represents a group of chemical compounds known as dibenzo- $p$-dioxins. Dubbed "the most potent animal carcinogen ever tested" and the "Darth Vader" of chemicals, dioxin gained particular notoriety in the 1970s and 1980s (Roberts, 1991). Elevated dioxin concentrations in U.S. surface waters were linked to effluent from pulp and paper mills utilizing chlorine bleaching methods. The Environmental Protection Agency conducted its first assessment of dioxin in 1981, and a revised assessment in 1985. During the 1980s some researchers argued that dioxin may do more to "promote" than to "initiate" cancer, resulting in claims that EPA overestimated the cancer risks associated with dioxin exposure. A 1987 reassessment of dioxin suggested that the cancer risk was seventeen times less than EPA's initial estimate. This estimate was developed by splitting the difference between two "irreconcilable" models of the carcinogenicity of dioxin (Powell, 1999).

Mechanistic research and a major epidemiological study conducted in the early 1990s confirmed the cancer risk associated with high levels of dioxin exposure, but suggested that low levels of dioxin result in negligible cancer risk. An EPA reassessment of dioxin in 1994 moderated the cancer risk for dioxin compounds, but introduced a new wrinkle: risk of noncancer effects at current background concentrations and exposures. The dioxin debate is therefore punctuated by value-based factors, none of which can be addressed or settled by recourse to "more objective" data and information:

- Whether the real policy issue is cancer or non-cancer health effects;

- Whether policy is intended to address high or low levels of dioxin;

- Whether policy should address the causation of cancer as opposed to the (mere) promotion of cancers.

\subsection{Aldrin/Dieldrin carcinogenicity}

In 1974, the Environmental Defense Fund ${ }^{6}$ petitioned the Environmental Protection Agency to suspend and cancel two pesticides, Aldrin and Dieldrin (A/D). A series of hearings were held to enable EPA to obtain public input regarding the effects of the proposed cancellation. The producer of A/D, Shell Chemical Company, argued that specific criteria must be satisfied in order for a substance to be considered carcinogenic. These criteria included toxicologic criteria such as development of tumors in two or more animal species exposed to the substance in a laboratory setting, proof that the tumors are related to the substance in question, and data proving the existence of at least one human cancer. EPA's position was based upon a different set of presuppositions and differ-

\footnotetext{
6 The Environmental Defense Fund is now known as Environmental Defense.
}

ent criteria for carcinogenicity. According to Agency scientists, "a carcinogen is any agent that increases the induction of even benign tumors in people or animals; a carcinogenic agent may be identified through analysis of experiments on animals or on the basis of properly conducted epidemiological studies; and any substance that produces tumors in one animal species in appropriately conducted tests must be considered a carcinogenic hazard to man" (Majone, 1989).

Neither Shell nor EPA's criteria could be dismissed as patently unreasonable or contrary to the norms of scientific procedure. Both positions were well documented, consistent with rigorous scientific protocol, and reproducible. Both employed quality-assured data and drew from relevant, peer-reviewed literature. In other words, it was not the case that one account was objective, while the other was somehow incorrect, invalid, or arbitrary. In their objection to Shell's requirement that at least one $\mathrm{A} / \mathrm{D}$-induced human cancer be clearly documented, EPA argued that since animal testing was sufficient to indicate risk, it would be ethically suspect to wait for a demonstration of human harm. Adopting a precautionary stance, EPA also argued that positive evidence of tumors in one animal species should weigh more heavily than negative results in other species (Majone, 1989).

\section{The upshot}

The three cases described above illustrate the nondeterministic and interpretive nature of scientific characterization and assessment. In all three cases, assessment of scientific research and monitoring lead to conclusions different from those that might have been drawn in a different context. None of the characterizations were simply "right" or "wrong"; rather, alternative conclusions were based on the "privileging" of different data, different models, different animating assumptions, and different analytical frameworks.

Martin Rein and Donald Schön address the importance of analytical framing in an essay entitled "Frame-Critical Policy Analysis and Frame-Reflective Policy Practice." Rein and Schön argue that many public controversies are intractable in the sense that science is not only unable to resolve the dispute but tends to exacerbate it by providing information that can be used in opposing ways by the sponsors of competing perspectives. Rein and Schön illustrate their contention through the path-breaking work of Paul Romer. Drawing primarily on the field of economic growth theory, Romer remarks upon the frequency of situations in which research leads to inconsistent, even incommensurable, results. What is striking to Romer is "how little disagreement there is about the facts." Rather, "differences concern the inferences about models [drawn] from the facts." Indeed, "many different inferences are consistent with the same regression statistics" (Romer, 1994). Rein and Schön amplify this point, arguing that "multiple theories are consistent with the same small number of facts, and there is no crucial experiment by which to discriminate among contending theories" (Rein 
and Schön, 1996). One of the central issues in scientific inquiry arises when a researcher must choose among multiple models, perspectives, or theories in an effort to characterize a particular set of facts. The same challenge holds true for the policy analyst or decision maker who must characterize alternative courses of action in terms of their conformance with the existing knowledge base.

As our case examples suggest, multiple policy alternatives can be consistent with existing knowledge. Indeed, as Jasanoff reminds, "the questions regulators need to ask of science cannot in many instances be adequately answered by science. There is ... general agreement that ... decisions have to made on the basis of available facts supplemented in large measure by judgement" (Jasanoff, 1990). It is this necessity to rely upon judgement that Helga Nowotny characterizes as the transgressiveness of scientific assessments. When acting in a policy context, scientists are not responding "to questions that they have chosen-in contrast to their research. Consequently, they are forced to transgress the limits of their competence." Likewise, scientific assessments "synthesize all available knowledge and of necessity transgress the boundaries of" scientific disciplines (Nowotny, 2003).

The classical notion of objectivity thus constitutes an implausible and unreasonable pre-condition for making information available to decision makers and the public. To support this assertion, let us look next at several case examples of how the Data Quality Act is actually being used.

\section{How the Data Quality Act is unfolding}

Interest groups and lobby organizations have wasted little time in submitting petitions for the correction and/or withdrawal of information claimed to be erroneous or invalid. As of April 2003 federal agencies had received approximately 60 petitions and/or other less formal requests for error correction; with some addressing relatively trivial matters (e.g., a mis-spelled name in a Social Security Administration database) and others addressing far more complex and technical issues. In FY 2003, the Department of Transportation received the most requests for correction with 38 ; while EPA received 13 petitions for the correction of information.

To better understand the implications of the Data Quality Act, let us consider three of the information correction petitions received by EPA.

\subsection{Atrazine}

Atrazine is a triazine herbicide that inhibits photosynthesis in sensitive plants, thus adversely affecting their ability to produce food to meet their energy needs. Atrazine is widely used on major food crops in growing regions across the United States. Acting under the Federal Insecticide, Fungicide, and Rodenticide Act, the Environmental Protection Agency has compiled an assessment of likely environmental effects of Atrazine use. ${ }^{7}$ This assessment forms part of the basis for an Interim Registration Eligibility Decision (IRED) that will determine whether atrazine can continue to be used and under what conditions. EPA's assessment of atrazine is based upon ecotoxicological data and microcosm and mesocosm studies submitted to support the registration process and discovered in the publicly available literature.

In the executive summary of the atrazine assessment document, EPA states the following:

[T] he Agency finds that in areas of high atrazine use, there is widespread environmental exposure that (1) has resulted in direct acute effects on many terrestrial plant species at both maximum and typical use rates, (2) may have caused direct effects on aquatic non-vascular plants which in turn could have caused reductions in primary productivity, (3) may have caused reductions in populations of aquatic macrophytes, invertebrates and fish, [and] (4) may have caused indirect effects on aquatic communities due to loss of species sensitive to atrazine and resulting in changes in structure and functional characteristics of the affected communities. Potential adverse effects on sensitive aquatic plants and other non-target aquatic organisms as well as their populations and their communities, are likely to be greatest where atrazine concentrations equal or exceed approximately 10 to $20 \mathrm{ug} / \mathrm{L}$ on a recurrent basis or over a prolonged time period. (Environmental Protection Agency, 2002a)

Citing the authority of the Data Quality Act, the Kansas Corn Growers Association (KCGA) and others filed a Request for Correction of EPA's atrazine assessment (Kansas Corn Growers Association, 2002). It is KCGS's contention that EPA published and disseminated inappropriate statements concerning the purported endocrine effects of atrazine. These statements, it is claimed, violate EPA and government-wide standards for data quality. Specifically, KCGA argues (2002) that "there are no validated test methods for assessing" whether atrazine causes endocrine effects" (in various organisms). To bolster this claim, KCGA cites consensus guidelines on the appropriate validation of toxicological methods, developed by a federal Interagency Coordinating Committee on the Validation of Alternative Methods (ICCVM, 1999).

Appropriate training and credentials would be required before one could responsibly join the debate concerning whether atrazine exposure is or is not associated with abnormal hormonal changes in frogs and other amphibians. However, the Executive Summary of the EPA IRED does not highlight or even allude to endocrine effects. On pages 90-94 (of a 95-page document), the agency summarizes three studies that address the possibility of endocrine effects in frogs. Although noting that atrazine effects "are

\footnotetext{
${ }^{7}$ Dated April 22, 2002, the atrazine assessment is entitled Registration Eligibility Science Chapter for Atrazine: Environmental Fate and Effects Chapter (Environmental Protection Agency, 2002a).
} 
a concern," the EPA assessment cites shortcomings in the reviewed studies, suggests that further research is needed, and - most importantly - makes no assertion regarding the overall likelihood of atrazine-related hormonal pathologies.

In responding to the KCGA petition, EPA officials note that the agency considers all available studies and information. As it turns out, many of the studies EPA considers as input to regulatory decision-making are the product of state-of-the-art procedures being employed at universities and other research establishments. By definition, cutting-edge research is not subject to established validation protocols. In this case the Data Quality Act is being used in an effort to amend or recall a government report that merely expresses "concern" over the possibility of generalized health-related effects of a particular chemical compound. ${ }^{8}$

\subsection{U.S. national climate change assessment}

In early 2003, the Competitive Enterprise Institute (CEI) petitioned the U.S. Office of Science and Technology Policy (OSTP) and the United States Global Climate Change Research Program (GCRP) to withdraw the 2002 U.S. Climate Action report (U.S. Department of State, 2002) because it uses information contained in the U.S. National Assessment on Climate Change (NACC; U.S. Global Change Research Program, 2000) which purportedly violates the objectivity requirements of the Data Quality Act." ${ }^{\text {9 }}$ Among other things, CEI asserts that the report was "published without development of the underlying science." More specifically, petitioners claim that the GCRP erred in it choice of models used to assess the potential impacts of climate change on selected U.S. resources. As stated in the CEI petition, "The basic rule of science is that hypotheses must be verified by observed data before they can be regarded as facts. Science that does not do this is 'junk science,' and at minimum is precisely what the [data quality act] is designed to bar from the policymaking process" (TheCre.com, 2003b).

It can be argued that the CEI position is based upon a fundamental misrepresentation of the NACC exercise. As clearly articulated in the Overview document, the synthesis process was not intended to predict specific future conditions or verify particular hypotheses. Rather the NACC is a scenario-based exercise designed to explore potential vulnerabilities to postulated changes in temperature and precipitation. As prominently stated early in the NACC document:

\footnotetext{
${ }^{8}$ In its response to KCGA, EPA explained that it would treat the request for correction as part of a comprehensive response to public comments concerning the IRED. In its response to public comments regarding the IRED, EPA disputed KCGA's interpretation and made minor editorial changes to the document to avoid ambiguity (Environmental Protection Agency, 2004).

9 The Competitive Enterprise Institute's petition letter to the Director of the Office of Science and Technology Policy (TheCre.com, 2003b).
}

Scenarios are plausible alternative futures-each an example of what might happen under particular assumptions. Scenarios are not specific predictions or forecasts. Rather, scenarios provide a starting point for examining questions about an uncertain future and can help us to visualize alternative futures in concrete and human terms .... Using scenarios helps to identify vulnerabilities and plan for contingencies. (U.S. Global Change Research Program, 2000)

The NACC Overview goes on to say, "[b]ecause we cannot predict many aspects of our nation's future climate, we have used scenarios to help explore U.S. vulnerability to climate change" (U.S. Global Change Research Program, 2000). In a section of the NACC entitled "Tools for Assessing Climate Change Impacts," the GCRP authors compare and contrast a set of seven available climate models available for use in the vulnerabilities assessment, noting that analysis relies predominantly on two models, one developed by the Canadian Climate Center and the other by the Hadley Centre in the United Kingdom. Both models used in the NACC have been peer reviewed and both incorporate similar assumptions about future emissions. With respect to the models selected for utilization in the analysis, the GCRP is quite clear:

For some aspects of climate the model results differ. For example, some models, including the Canadian model, project more extensive and frequent drought in the US, while others, including the Hadley model, do not. The Canadian model suggests a drier Southeast in the 21st century while the Hadley model suggests a wetter. In such cases, the scenarios provide two plausible but different alternatives. (U.S. Global Change Research Program, 2000)

The U.S. National Assessment is a model-based review of alternative future scenarios designed to suggest potential vulnerabilities and adaptation strategies. Given this, it might be fair to criticize the GCRP for not doing enough to emphasize that the NACC is not a predictive report (e.g., by referring to scenarios as "plausible" the NACC begs the question "how plausible") because of its failure to utilize alternative approaches to modeling for scenario development. Nevertheless, it is well understood that models of complicated systems are not "truth machines," but primarily tools to generate insights relevant to decisions (Wynne and Shackley, 1994). In this context it is perhaps instructive to consider the reflections of one of the world's premier environmental modelers:

I have often conceived of models as 'teaching machines' that can help us to sort out relationships among many factors, but their credibility comes primarily from a combination of the reasonableness of their underlying structural assumptions and both heuristic and formal validation protocols. However, for complex nonlinear systems, intuitive or theoretical insights often follow, rather than precede model applications. Thus, to me, it 
is not very important whether such insights of necessity required or did not require model explorations to be uncovered, but rather that models are an integral component of the community process of exploring the character of complex systems. (Schneider, 1997)

Consistent with Schneider's formulation, the purpose of the NACC exercise was not to predict regional-scale climate change, but rather to characterize how resources might react to changes in critical climatic variables. Essentially asking a series of "what if" questions, the NACC was an exercise in science-based contingency analysis, enlightening planners, decision makers, and the public regarding how stipulated changes in precipitation and temperature might impact, say, coastal and marine resources in the Southeast or agriculture in the Great Plains. ${ }^{10}$

\subsection{Integrated Risk Information System (IRIS) and barium}

The Integrated Risk Information System (IRIS) is an electronic database containing information on human health effects that may result from exposure to various chemicals in the environment. ${ }^{11}$ in this essay or access the IRIS Web site at: http://www.epa.gov/iris/intro.htm. The IRIS was initially developed for EPA staff in response to a growing demand for consistent information on chemical substances for use in risk assessments, decision-making, and various regulatory activities. The heart of the IRIS system is a collection of computer files covering individual chemicals. These files contain (1) oral reference doses and inhalation reference concentrations for chronic noncarcinogenic health effects; and (2) hazard identification, oral slope factors, and oral and inhalation unit risks for carcinogenic effects. The EPA makes it clear that IRIS is a tool designed and maintained to provide hazard identification and dose-response assessment information, but not to provide situational information on specific instances of exposure. ${ }^{12}$ In other words, IRIS data must be combined with specific exposure information in order to contribute to risk characterization and/or risk management decisions.

In October 2002, EPA received a petition from Chemical Products Corporation (CPC) requesting that the agency correct the IRIS file dealing with barium and barium compounds. Specifically, CPC charges that the IRIS barium file does not contain "scientifically sound hazard assessment because it identifies hypertension as the critical effect. A scientifically sound assessment would identify kidney effects as the critical effect" (Chemical Products Corporation, 2002). Given this, CPC goes on to claim that the oral reference dose

\footnotetext{
${ }^{10}$ In its response to CEI, EPA noted that the U.S. Department of State (DoS) had actually disseminated the CAC (not EPA) and invited the petitioner to pursue the matter with DoS (Environmental Protection Agency, 2004).

11 For more information on IRIS, see Exhibit 1

12 Conventionally understood, the risk assessment process consists of four distinct steps: (1) hazard identification, (2) dose-response assessments, (3) exposure assessment, and (4) risk characterization.
}

in the IRIS barium file $(0.21 \mathrm{mg} / \mathrm{kg} / \mathrm{day})$ is too low, citing another EPA study that failed to document barium-related health effects below a level of $180 \mathrm{mg} / \mathrm{kg} /$ day.

The question of whether to base a reference dose on acute hypertension or (chronic) renal toxicity is inherently multi-faceted, involving not only toxicological data and conventions, but also a host of value-based propositions concerning which health-related pathologies are or are not appropriately addressed under the context of EPA's mission. While one would need training in toxicology to adequately evaluate CPC's contentions, ${ }^{13}$ the basic question at issue what types of human health risks should EPA report to the public - is not subject to a strictly toxicological interpretation, and embeds manifold and profoundly important value commitments about public health and the environment. The CPC petition transgresses the confines of traditional scientific objectivity, essentially smuggling a wide range of issues under cover of a debate over alternative modes of toxicological characterization.

\section{Institutionalizing a mischaracterization in science-policy assessment: on the very notion of objectivity as a dichotomous and deterministic construct}

Although addressing different environmental issues, the three petitions outlined above are actually quite similar: all argue that government disseminated information products are based upon or incorporate scientific inputs that are essentially invalid. Let us look more closely at this assertion.

As science historian Naomi Oreskes reminds us, the word "valid" is synonymous with the words "correct," and "true." In Webster's New Collegiate Dictionary we find that "valid" implies being supported by objective truth. In other words, as concepts validity and objectivity are closely bundled together, and both are understood as opposite of words such as "false," "incorrect," and "untrue." In the arena of science-policy assessment, this dichotomy can be extremely misleading.

Scientists in academia and other research institutions are typically scrupulous in how they establish and confirm the validity of research findings. Indeed, the notion of validity is parsed into various components, each with its own threats and assessment requirements. In their classic text on research methodologies, Thomas Cook and Donald Campbell define four basic aspects of validity: statistical conclusion validity, internal validity, construct validity, and external validity. (Cook and Campbell, 1979). Neither the Data Quality Act nor OMB's guidance to federal agencies attempts to address validity in the rigorous and nuanced sense out-

\footnotetext{
${ }^{13}$ In a 1994 review, the U.S. National Research Council concluded that IRIS "has quality problems and is not fully referenced." Other critics complain that IRIS "oversimplifies complex information and does not adequately convey the uncertainty in its summary information" (Powell, 1999). For a more thorough treatment, see Powell (1999).
} 
lined by Cook and Campbell. Rather, OMB adopts a usage much more closely aligned with that of everyday language, in which objectivity is understood simply as information that is "accurate, reliable, and unbiased" (Noe et al., 2003). In other words, the Data Quality Act, OMB's guidance, and Data Quality Act proponents seem to either explicitly adopt or implicitly accept a characterization of science assessment in which outputs are unambiguous and deterministic, either valid or invalid, reliable or unreliable, or biased or unbiased.

The call for such dichotomous validation is an implicit invocation of the "hypothetico-deductive model of science, namely, that scientific theories can be thought of as statements that entail logically necessary deductive consequences" (Oreskes, 1998). Although intellectually tidy, there are profound problems with this presupposition. As many philosophers of science have realized, the hypothetical-deductive model assumes closed systems. Drawing again from Oreskes (1998), "A statement of the form $p$ entails $q$ works if and only if the statement describes a closed system. But a closed system is a philosophical ideal, not a natural kind." This is why environmental and public health mission agencies rarely find themselves in a position to adopt science-based policy positions that can be said to be fully validated.

As demonstrated through the case examples, sciencebased information products disseminated by governmental agencies rarely address issues that can be adequately characterized in terms of discrete, dichotomous variables. Rather, scientifically based information products frequently address complex phenomena such as the relationship between precipitation, temperature, and disease vectors under alternative scenarios of global warming in a specific regional context; the comparative efficiency of alternative HIV/AIDS intervention programs for particular ethnic populations; or mixed-use management of aquatic and terrestrial resources in a specific river basin under a range of population growth assumptions. Issues such as these are transgressive, and cannot be adequately characterized by means of one or two variables or metrics of concern. Rather, they involve the integration of dozens of different data sets, numerous and varied models, and findings from perhaps hundreds of separate studies (Herrick and Jamieson, 1995).

Policy and regulatory regimes are typically based upon a wide variety of informational inputs, some of which are more robust than others. Over the past quarter century, government scientists and regulators have worked with national academies and the academic community to evolve a process known as weight-of-evidence assessment. The weight-of-evidence approach generally considers all relevant information in an integrative assessment, taking into account the kinds of evidence available, the quality and quantity of the evidence, the strengths and limitations associated with each type of evidence, and explains how the various types of evidence fit together (Environmental Protection Agency, 1986, 1996). For example, considerations in assessing published information about chemical toxicity would include factors such as the quality of testing method, size and power of the study design, and biological plausibility of exposure-response relationships. In this approach, a well-developed, peer-reviewed study would generally be accorded greater weight than information derived from a less well-developed study that had not been peer-reviewed. However, if no other data were available, the exiengencies of the regulatory process may warrant or even compel consideration of studies that have not been peer-reviewed or published in the open literature.

While EPA and other federal agencies have developed protocols and various "classification schemes" to help staff scientists and analysts apply the weight-of-evidence approach, it is unreasonable to expect that the approach will produce results that are simply true or false. As Powell writes,

Unlike biology, chemistry, or physics, risk assessment is not an "organic" scientific discipline. Instead the field arose to respond to the needs of decision-makers who frequently pose policy-relevant questions that cannot - and may never - be definitively answered by science. Scientifically plausible environmental risk assessments can differ by multiple orders of magnitude ... Therefore, risk assessment is distinct from scientific disciplines that verifiably test hypotheses. (Powell, 1999)

Although informed by the findings and methods of disciplinary science, the weight-of-evidence approach is nevertheless - and of necessity - a transgressive, judgmental exercise. While the weight-of-evidence approach is formally recognized in the regulatory context, the same basic philosophy of information integration applies to other forms of decision-making and to the compilation of information products or public discourse. ${ }^{14}$ In all cases, the heart of a weight-of-evidence assessment is invariably a narrative summary of the strengths and weaknesses of the considered body of material.

\section{Putting the Data Quality Act in context}

The Data Quality Act requires that federal agencies provide a way for individuals affected by erroneous data to seek redress, either by correcting the information product in question or through cessation or limitation of its dissemination. If the agency refuses to address the discrepancy, the affected party can appeal the agency's decision. Opinions vary concerning the nature and likely extent of the appeals process, but some interpret it to mean that affected parties can sue the agency to compel correction and/or retraction of allegedly faulty information (Noe et al., 2003; Horvath,

\footnotetext{
14 Jasanoff describes a wide variety of epistemic communities associated with specific issues of science-policy assessment. Such communities of inquiry often evolve consensus standards or protocols to help guide ongoing discussions concerning disposition of the issue (see for example, Jasanoff, 1990, pp. 84-180; and Jasanoff, 1996).
} 
2002). It remains to be seen whether agency implementation of the Data Quality Act is subject to judicial review. While many agency guidelines adopt the position that Section 515 does not support judicial review, ${ }^{15}$ OMB appears to leave the question open (U.S. Office of Management and Budget, 2002).

In the U.S., judicial reviewability tends to hinge upon whether an action has binding consequences upon the agency or regulated parties. To be considered reviewable, an action or information product must be tied to a clear sequence of regulatory actions. For example, "in Whitman v. American Trucking Associations, Inc., 531 U.S. 457 (2001), the Supreme Court considered the reviewability of an EPA implementation policy described in the preamble of an agency regulation" (Raul and Zampa, 2002). Although EPA argued that this policy was preliminary and not binding on states or the public, the Supreme Court ruled that finality was supplied by the later publication of implementation procedures under a heading entitled "Final Decision." Following a similar logic, the United States Court of Appeals for the District of Columbia recently ruled that publication by the Department of Health and Human Services of a biennial Report on Carcinogens was a reviewable agency action because it triggered obligations on the part of states and other federal agencies "to consider" the report's contents. However, it remains unclear whether a free-standing report or Web site can be viewed as a final agency action, and thus subject to review.

The case for judicial review of agency science is frequently founded upon the Administrative Procedures Act (APA). The APA is the general federal statute establishing court review of agency actions. Specifically, the APA authorizes courts to review and determine whether agency actions are "arbitrary, capricious, an abuse of discretion, or otherwise not in accordance with law" (U.S. Code Collection, 5 U.S.C. 706(2)(A)). Industry has proposed that the APA be used to expand judicial review of agency information disclosures, especially when information products contain "a strong policy content and private sector impact," or are based on publicly disseminated information that is false or misleading (Business Roundtable, 2001). A somewhat obscure aspect of the Data Quality Act requires agencies to exercise a greater degree of quality and transparency when preparing and disseminating so-called "influential" information prod-

\footnotetext{
15 As an example, EPA's Information Quality Guidelines contain the following notification: "EPA's Guidelines are intended to carry out OMB's government-wide policy regarding information we disseminate to the public. Our Guidelines reflect EPA's best effort to present our goals and commitments for ensuring and maximizing the quality of information we disseminate. As such, they are not a regulation and do not change or substitute for any legal requirements. They provide non-binding policy and procedural guidance, and are therefore not intended to create legal rights, impose legally binding requirements or obligations on EPA or the public when applied in particular situations, or change or impact the status of information we disseminate, not to contravene any other legal requirements that may apply to particular agency determinations or other actions" (Environmental Protection Agency, 2002b, p. 4).
}

ucts. As defined by OMB, influential information is "data or information the dissemination of which will or does have a clear and substantial impact on important public policies or private sector decisions" (U.S. Office of Management and Budget, 2002). Influential information, then, is inherently action inducing, thus partially bridging the gap between mere dissemination and agency action as understood under U.S. case law. ${ }^{16}$

\section{If not objectivity, what?}

If we dismiss the classical conception of objectivity as a precondition for policy action, where does that leave us? Are we then committed to some type of relativism in which any characterization is as good as the next? Absolutely not. Information quality resides not so much with the imposition of dichotomous constructs such as objectivity and validity, but rather in something more akin to narrative coherence. Most typically employed in fields such as literary criticism, narrative coherence is a function of many attributes, including contextual and/or procedural relevance, methodological rigor, and transparency. Majone provides an especially apt depiction of how things really work:

The structure of [a policy] argument will typically be a complex blend of factual statements and subjective evaluations. This unavoidable complexity makes any direct, informal testing of the argument quite impossible. Whatever testing is done must rely on a variety of standards that depend on the analytic methods employed, on the plausibility and robustness of the conclusions, and on agreed-upon criteria of adequacy and effectiveness. (Majone, 1989, p. 10)

In a policy context, science helps to furnish and bound a solution space. The overall solution space is a broad-ranging narrative that integrates a wide variety of diverse factors including ethical percepts, public values, stakeholder interests, institutional charters, organizational cultures, legal stipulates, historical conventions, political-ideological convictions, convergence or consistency with other policy priorities, available resources, and the epistemic perspectives of elites and other involved actors. And as Bozeman and Landsbergen have argued, the credibility of such a solution space "may be a function of evidence presented, the structure and logic of the arguments, and the ... content of the propositions advanced, [often hinging on] a complex mix of cues and decision stimuli, a mix that may be unique" to decision

\footnotetext{
${ }^{16}$ The importance of so-called influential information has recently been amplified by OMB's development and publication of a government-wide guidance document addressing the peer review practices of federal agencies. Developed pursuant to the Data Quality Act and focused exclusively on influential scientific information, OMB's Peer Review Bulletin establishes minimum standards for when peer review is required and how extensive the review should be for different information products (U.S. Office of Management and Budget, 2004).
} 
makers and/or decision contexts (Bozeman and Landsbergen, 1989). In a very real sense, then, a policy is a story, and the utility of any particular scientific characterization depends at least as much on its place and role within the overall narrative as it does upon internal factors such as precision, bias, or statistical power. Under this perspective, the weight-of-evidence model should be viewed as a narrative framework composed of various scientific findings linked as a series of topically related vignettes. The strength of the policy or information product is thus a function of the overall coherency, plausibility, and compellingness of the narrative as a whole. It is inherently difficult, then, to argue that an entire document - such as the National Assessment of Climate Change or the Atrazine IRED - can be invalidated because a particular scientific characterization is uncertain or open to question. The narrative itself establishes and warrants the validity and utility of its constituent elements. As demonstrated earlier, scientific findings are "open textured," and if considered independent of an overall application or narrative, each element is inherently contestable.

The integration of scientific information to support a particular policy or regulatory regime is a challenging proposition, involving both science and judgment. As Emery Roe points out, the policy formulation process is characterized by uncertainty, complexity, and incompleteness. Issues are uncertain when causal processes are unclear or not easily understood. Issues are complex when they are more numerous, varied, or interrelated than previously understood. Issues are incomplete when interrupted, postponed or left otherwise unfulfilled in some important aspect. This lack of epistemic grounding could result in paralysis, but it tends not to. Policy makers muddle through, usually by appealing to theories and operating within administrative frameworks that accommodate complexity, uncertainty, and incompleteness (Roe, 2001). ${ }^{17}$ This is especially true in areas such as public health and environmental policy where decision makers frequently utilize adaptive policy instruments to account for and/or react to unanticipated factors and changing conditions (Berry et al., 1998; Lee, 1993).

In such a context, it is probably impossible and unwise to pre-stipulate measures of acceptable information quality. Information use is highly idiosyncratic and application dependent, drawing validity from its place and role within a larger narrative (Herrick, 2002; Eagleton, 1998).

The Data Quality Act poses a review framework that is fundamentally inconsistent with that applied under the APA. Under the "arbitrary and capricious" standard, courts are compelled to consider information in terms of the context and circumstances of its application; the "objectivity" standard, on the other hand, highlights only the internal coherence of a specific datum or scientific characterization. This distinction is profound. As discussed earlier, the APA is focused on agency actions. Courts can override, sanc-

\footnotetext{
17 "Muddling through" is well documented in the public policy and management literature (Wilson, 1989).
}

tion, stay, or reverse agency acts found to be "arbitrary and capricious." 18 The Data Quality Act is potentially significant because it creates standing to extend this power from the realm of administrative action into the realm of information dissemination and expression, especially as regards so-called "influential" information. If interpreted rigidly and broadly, it seems likely that the Data Quality Act will tend to ossify the regulatory process, through creation of a formal administrative process that creates standing and provides a venue through which to debate issues that are essentially interminable.

\section{A coda: abetting the politicization of science}

In Washington circles, 'sound science' has become the remedy of choice for much of what ails the regulatory system. Whether it's arsenic in drinking water or particulates in the air, proponents of this seemingly simple solution argue that if [EPA] would only get more scientists and listen to their sage advice, we could eliminate or at least reduce excessive regulations and address far more urgent problems" (Greer and Steinzor, 2002). Indeed, some scientists believe that 'science' alone provides a sufficient basis for decision-making, in that "a problem is identified, various hypotheses are tested, remedial policies suggested and implemented-then the situation improves" (Lovejoy, 2002). But as Roger Pielke points out, "putting the onus of problem resolution onto science brings all the messy realities of politics into the practice of science. Rather than making politics more scientific, this approach, in fact, makes science more political," resulting in a sort of "diversionary re-framing" that causes political battles to be waged in the language and protocol of science and scientific results (Pielke, 2002b; Freudenburg et al., 1988). There are good reasons to anticipate that the Data Quality Act will not contribute to the rationalization of environmental and public health policy or the responsible dissemination of information to the public. An instrument that enables scientific facts to be removed from their narrative context is a tool of advocacy and politicization, not reasoned analysis or assessment. The Data Quality Act essentially turns the notion of objectivity into a sort of fetish, and provides a formal administrative mechanism to separate scientific information from the context of its application.

The debate surrounding The Skeptical Environmentalist also treats scientific objectivity as a misguided obsession, with opponents and proponents alike filling reams of paper in attempts to demonstrate that Lomborg either did or did not comport with established scientific canons and provide

\footnotetext{
${ }^{18}$ Under environmental statutes such as the Toxic Substances Control Act (TSCA) and the Federal Insecticide, Fungicide and Rodenticide Act (FIFRA), EPA is subject to a "substantial evidence" standard that is more demanding that the APA's "arbitrary and capricious" standard. Either way, scientific data and information are assessed from within the context of a larger, or covering narrative.
} 
a valid account of the environmental issues addressed in his book. As argued in this essay, scientific data and findings tend to be value neutral. Depending on its role within a policy or deliberative narrative, the same fact can be used to support diametrically opposed perspectives, and the same problem can yield equally valid sets of conflicting facts. As Sarewitz puts this:

$[\mathrm{W}] \mathrm{e}$ are not suffering from a lack of objectivity, but from an excess of it. Science is sufficiently rich, diverse, and Balkanized to provide comfort and support for a range of subjective, political positions on complex issues such as climate change, nuclear waste disposal, acid rain, or endangered species. The problem is not one of good science versus bad, or "sound" science versus "junk" science. The problem is that nature can be viewed through many analytical lenses, and the resulting perspectives do not add up to a single, uniform image, but a spectrum that can illuminate a range of subjective positions. (Sarewitz, 2000)

Writing in this volume, Harrison contends that Lomborg's critics are at least as focused on the potential applications of The Skeptical Environmentalist as they are upon specific instances of scientific mischaracterization. Indeed, one of the most "commonly recurring arguments advanced against the book is the charge that it plays to a particular agenda and can be used by vested corporate and political interests" (Harrison, in press).

Such claims appear oblivious to the fact that all assessments adopt some type of perspective. As has been argued in this essay, science-based assessment is a synthetic exercise in which practitioners must utilize one analytical framework rather than another, or tackle a problem from within the epistemic bounds of one discipline or set of disciplines as opposed to others. It is not inherently "dishonest" to work from a particular perspective; it is however, a distraction to argue that there is such a thing as an "immaculate assessment," perfectly objective and free of any analytical, social, epistemic, political, cultural, or psychological influence. As outlined in this essay, the development - and by implication, evaluation - of a policy narrative is a multi-faceted proposition that transgresses the bounds of any single discipline or perspective. Science assessment is a synthesizing activity dependent on the exercise of judgement.

The language used by Lomborg in the introductory pages of The Skeptical Environmentalist could - and in my opinion, should - have been more modest, constrained, and limited. It is fantastical to claim that one can describe "the real state of the world" in a single volume (Lomborg, 2001, p. 3). Be that as it may, Lomborg, like the Worldwatch reports he wishes to counter, utilizes scientific data and information in an assessment context, which by definition, means that he adopts a perspective. Those of us who disagree with Lomborg's synthesis monograph are perfectly welcome to craft and publish refutitive narratives. Indeed, as Majone re- minds,

There is no unique way to construct an argument: data and evidence can be selected in a wide variety of ways from available information, and there are ... alternative methods for analysis and ways of ordering values. There is nothing intrinsically reprehensible in selecting a particular combination of data, facts, values, and analytic methods that seems to be the most appropriate to convince people who have to carry out [or support a] decision. (Majone, 1989)

All sides of the Lomborg debate seem to have lost sight of the basic truth that science assessments are inherently transgressive and that scientific findings do not speak for themselves. In the context of science-policy assessment, the notion of an overarching objectivity is chimerical, and its exercise does little but misdirect debate away from the overall coherence (or lack thereof) of policy narratives.

\section{Acknowledgements}

I would like to acknowledge input from Roger Pielke, Dan Sarewitz, and Jennifer Cranford.

\section{References}

Berry, J., Brewer, G., Gordon, J., Patton, D., 1998. Closing the gap between ecosystem management and ecosystem research. Policy Sci. 31, 55-80.

BNA Inc., 2003. EPA will consider all studies in decisions on regulation of chemicals. BNA Environ. Rep. 22 (February 3), A-14.

Bozeman, B., Landsbergen, D., 1989. Truth and credibility in sincere policy analysis. Eval. Rev.: J. Appl. Social Sci. 13 (4), 335-379.

Business Roundtable, 2001. Blueprint 2001: Drafting Environmental Policy for the Future. The Business Roundtable, Washington, DC. Available: http://www.brtable.org/document.cfm/496.

Chemical Products Corporation, 2002. Request for correction of IRIS barium and compounds substance file-information disseminated by EPA that does not comply with EPA or OMB information quality guidelines. On file with author.

Clark, W.C., Majone, G., 1985. The critical appraisal of scientific inquiries with political implications. Sci. Technol. Hum. Values 10 (3), 6-19.

Clean Air Report, 2002. White House releases advisory on agency data quality guidelines, 13 (13).

Cook, T., Campbell, D., 1979. Quasi-Experimentation: Design and Analysis Issues for Field Settings. Houghton Mifflin Company, Boston, MA.

Davies, J.C., 1996. Comparing Environmental Risks. Resources for the Future, Washington, DC.

Eagleton, T., 1998. Literary Theory. University of Minnesota Press, Minneapolis, MN.

Echeverria, J.D., Kaplan, J.B., 2002. Poisonous Procedural Reform: In Defense of Environmental Right to Know. Georgetown Environmental Law and Policy Institute, Georgetown University Law Center, Washington, DC.

Environmental Protection Agency, 1986. EPA's guidelines for carcinogen risk assessment. Federal Register 51 (185), 33992-34003. Available: http://www.epa.gov/ncea/raf/. 
Environmental Protection Agency, 1996. EPA's proposed guidelines for carcinogen risk assessment. Federal Register 61 (79), 17960-18011. Available: http://www.epa.gov/ncea/raf/.

Environmental Protection Agency, 2002a. Registration Eligibility Science Chapter for Atrazine: Environmental Fate and Effects Chapter. Available: http://www.epa.gov/oppsrrd1/reregistration/atrazine/efed_red chap_22apr02.pdf.

Environmental Protection Agency, 2002b. Guidelines for Ensuring and Maximizing the Quality, Objectivity, Utility, and Integrity of Information Disseminated by the Environmental Protection Agency. Environmental Protection Agency, EPA/260R-02-008, Washington, DC.

Environmental Protection Agency, 2004. U.S. Environmental Protection Agency Information Quality FY03 Annual Report. United States Environmental Protection Agency, Washington, DC. Available: http://www.epa.gov/oei/qualityguidelines.2004.

Fischhoff, B., Bostrom, A., Quadrel, M.J., 1993. Risk perception and communication. Annu. Rev. Public Health 14, 183-203.

Freudenburg, W., Frickel, S., Dwyer, R., 1988. Diversity and diversion: higher superstition and the danger of insularity in science and technology studies. Int. J. Sociol. Social Policy 18 (5/6), 634.

Greer, L., Steinzor, R., 2002. Bad Science. Environ. Forum 19 (1), 28-43.

Harrison, C., in press. Peer review, politics and pluralism. Environ. Sci. Policy 7, 357-368.

Herrick, C., 2002. The data quality act: an exchange. Ogmius No. 3. Available: http://sciencepolicy.colorado.edu/ogmius/archives/issue_ 2/response.html.

Herrick, C., Jamieson, D., 1995. The social construction of acid rain: some implications for science/policy assessment. Global Environ. Change 5 (2), 105-112.

Herrick, C., Jamieson, D., 2001. Junk science and environmental policy: obscuring public debate with misleading discourse. Philos. Public Policy Q. 21 (Spring), 11-16.

Horvath, S., 2002. New law will let business attack data underlying rules. The Wall Street Journal, July 5.

ICCVM, 1999. Evaluation of the validation status of toxicological methods: general guidelines for submissions to ICCVM. Prepared by the Interagency Coordinating Committee on the Validation of Alternative Methods, October, p. v.

Jasanoff, S., 1990. The Fifth Branch: Science Advisers as Policymakers. Harvard University Press, Cambridge.

Jasanoff, S., 1996. The dilemma of environmental democracy. Issues in Science and Technology, Fall, 63-70.

Kaiser, J., 2003. Wielding the data-quality cudgel. Science 299 (5614), 1837.

Kansas Corn Growers Association, 2002. Request for Correction of Information Contained in the Atrazine Environmental Risk Assessment. EPA Docket No. OPP-34237A.

Kuhn, T., 1970. The Structure of Scientific Revolutions. The University of Chicago Press, Chicago, IL.

Lee, K., 1993. Compass and Gyroscope: Integrating Science and Politics for the Environment. Island Press, Washington, DC.

Lomborg, B., 2001. The Skeptical Environmentalist. Cambridge University Press, Cambridge.

Longino, H., 1990. Science as Social Knowledge: Values and Objectivity in Scientific Inquiry. Princeton University Press, Princeton, NJ.

Lovejoy, T., 2002. Biodiversity: dismissing scientific process. Scientific American.com, January. Available: http://www.sciam.com/article.cfm? articleID=000F3D47-C6D2-1CEB93F6809EC5880000\&pageNUMBER $=12 \&$ catID $=2$.

Madison, J., 1910. Letter to W.T. Barry, August 4, 1822. In: Hunt, G.P. (Ed.), The Writings of James Madision. G.P. Putnam's Sons, New York.

Majone, G., 1989. Evidence, Argument, and Persuasion in the Policy Process. Yale University Press, London and New Haven.

National Research Council, 1989. Improving Risk Communication. National Research Council, Washington, DC.
Noe, P., Anderson, F., Shapiro, S., Tozzi, J., Hawkins, D., Wagner, W., 2003. Learning to live with the Data Quality Act. Environ. Law Rev. 33, 10224-10236.

Nowotny, H., 2003. Democratising expertise and socially robust knowledge. Sci. Public Policy 30 (3), 151-156.

Oreskes, N., 1998. Evaluation (not validation) of quantitative models. Environ. Health Perspect. 106 (6), 1453-1460.

Pielke Jr., R.A., 2002a. Flying blind: the data quality act and the atmospheric sciences. Weatherzine 33. Available: http://sciencepolicy. colorado.edu/zine/archives/33/editorial.html.

Pielke Jr., R.A., 2002b. Policy, politics and perspective. Nature 416, 367-368.

Planin, E., 2002. Moving target on policy battlefield. The Washington Post, May 2.

Powell, M.R., 1999. Science at EPA: Information in the Regulatory Process. Resources for the Future, Washington, DC.

Raul, A.C., Zampa, J.M., 2002. Deeper judicial scrutiny needed for agencies' use of science. Andrews Asbestos Litigation Rep. 24 (7), $1-5$.

Regulation: The Cato Review of Business and Government, 2002. Information disseminated by federal agencies. Regul. Mag. 25 (3), 4

Rein, M., Schön, D., 1996. Frame-critical policy analysis and frame-reflective policy practice. Knowledge Policy: Int. J. Knowledge, Transfer Utilization 9 (3), 85-104.

Revkin, A., 2002. Law revises standards for scientific study. The New York Times, March 21.

Roberts, L., 1991. Dioxin risks revisited. Science 251, 624-626.

Roe, E., 2001. Varieties of issue incompleteness and coordination: an example from ecosystem management. Policy Sci. 34, 111133.

Romer, P., 1994. The origins of endogenous growth. J. Econ. Perspect. 8 (2), 3.

Russell, M., Arrow, K., Bailar, J., Gordon, J., Hilst, G., Levin, S., Malone, T., Nierenberg, W., Starr, C., Tukey, J., 1991. The Experience and Legacy of NAPAP. Report to the Joint Chairs Council of the Interagency Task Force on Acidic Deposition, Oversight Review Board of the National Acid Precipitation Assessment Program, NAPAP, Washington, DC.

Sarewitz, D., 2000. Science and environmental policy: an excess of objectivity. In: Frodeman, R. (Ed.), Earth Matters: The Earth Sciences, Philosophy, and the Claims of Community. Prentice Hall, New York.

Schneider, S., 1997. Integrated assessment modeling of global climate change: transparent rational tool for policy making or opaque screen hiding value-laden assumptions? Environ. Model. Assess. 2, 229249.

Schulkin, J., 1992. The Pursuit of Inquiry. State University of New York Press, Albany, NY.

TheCre.com, 2003a. Center for Regulatory Effectiveness. Available: http://www.thecre.com/.

TheCre.com, 2003b. Center for Regulatory Effectiveness. Data Quality Act. US, February 20. Available: http://thecre.com/quality.

U.S. Code Collection, 44 U.S.C. 3502(1).

U.S. Code Collection, 5 U.S.C. 706(2)(A).

U.S. Department of State, 2002. U.S. Climate Action Report 2002, Washington, DC, May.

U.S. Global Change Research Program, 2000. Climate Change Impacts on the United States: The Potential Consequences of Climate Variability and Change. Cambridge University Press, New York.

U.S. Office of Management and Budget, 2002. Guidelines for Ensuring and Maximizing the Quality, Objectivity, Utility, and Integrity of Information Disseminated by Federal Agencies. Office of Management and Budget, Executive Office of the President, January 3. Available: http://www.whitehouse.gov/omb/fedreg/reproducible.html.

U.S. Office of Management and Budget, 2004. Revised Information Quality Bulletin for Peer Review, April 15. Available: http://www. whitehouse.gov/omb/inforeg/peer_review041404.pdf.

Wachbroit, R., 2001. Understanding the consumer's right to know. Philos. Public Policy Q. 21 (4), 25-31. 
Wagner, W., 2004. The "Bad Science" fiction: reclaiming the debate over the role of science in public health and environmental regulation. Law Contemp. Probl. 66, 63-133. Available: http://www.law.duke.edu/ shell/cite.pl?66+Law+\&+Contemp.+Probs.+63+(Autumn+2003).

Wilson, J.Q., 1989. Bureaucracy: What Government Agencies Do and Why They Do It. Basic Books, New York.

Winstanley, D., 2000. In support of skepticism. Environ. Sci. Policy 3, 19-20.

Wynne, B., Shackley, S., 1994. Environmental models: truth machines or social heuristics. Globe 21, 6-8.
Charles Herrick is vice president of Stratus Consulting, Inc., in the firm's Washington, DC office. Prior to joining Stratus, Herrick was Associate Director of the White House Council on Environmental Quality (CEQ). Working in support of U.S. governmental programs, he has more than 17 years of experience in environmental information policies and applications, environmental program management and evaluation, applied environmental policy analysis, and science/policy assessment in an environmental context. Dr. Herrick holds a Ph.D. in public policy from the American University in Washington, DC. 